\title{
Safety Assessment of Damaged Multi-planar Square Hollow Section Welded Joints Using the New BS 910:2013+A1:2015
}

\author{
Seng Tjhen Lie, Vipin Sukumara-Pillai* \\ School of Civil and Environmental Engineering, Nanyang Technological University, Singapore
}

Email address:

vipin1@e.ntu.edu.sg (V. Sukumara-Pillai)

${ }^{*}$ Corresponding author

To cite this article:

Seng Tjhen Lie, Vipin Sukumara-Pillai. Safety Assessment of Damaged Multi-planar Square Hollow Section Welded Joints Using the New BS 910:2013+A1:2015. Advances in Applied Sciences. Vol. 4, No. 1, 2019, pp. 11-22. doi: 10.11648/j.aas.20190401.12

Received: March 19, 2019; Accepted: April 26, 2019; Published: May 17, 2019

\begin{abstract}
The safety assessment procedure in the new BS 7910:2013+A1:2015 guide is based on the failure assessment diagram (FAD) method. This paper aims to validate the above procedure for complex geometries such as damaged multi-planar square hollow section (SHS) welded joints and to recommend optimal solutions if necessary. FAD curves are constructed for cracked multi-planar SHS TT-, YT- and KT-joints for the first time and are compared with the Option 1 curve of the BS guide. A robust novel automatic finite element (FE) mesh generator, which is validated using the full-scale experimental test results, is used in this study. The new FE mesh generator addresses the issue of non-convergence by using a key-hole for the modelling the crack tip in elastic-plastic analyses. The new FE mesh generator is capable to model cracks and geometries of arbitrary dimensions and is able to achieve convergence of solutions even at a high plastic deformation. It is shown to be aiding in speedy generation of cracked FE mesh models which is otherwise time consuming to generate using commercial software packages. The results show that the Option 1 curve does not always guarantee safe solutions for multi-planar SHS welded joints. Hence, a penalty factor of 1.1 is recommended to be used to calculate the plastic collapse load. The use of proposed penalty factor gives optimal solutions for cracked multi-planar SHS TT-, YT- and KT-joints.
\end{abstract}

Keywords: Failure Assessment Diagram, Finite Element Mesh Generator, $J$-integral, Multi-planar Welded Joint, Surface Crack, Square Hollow Section

\section{Introduction}

A common issue faced by designers of offshore structures concerns the joints between the tubular members which must be assessed for plastic collapse, fatigue and fracture. Square hollow sections (SHS) tubular welded joints are one of the typical joints which are commonly found at the top-side of offshore platforms. The structural behaviour of these joints is governed by plastic collapse (yielding) and/or crack extension (fracture). There is lack of reported works on plastic collapse and fracture behaviour of cracked multiplanar SHS TT-, YT- and KT-joints till date and therefore, the current study addresses this research gap by focussing on these joints.

BS 7910:2013+A1:2015 [1], Guide to Methods for Assessing the Acceptability of Flaws in Metallic Structures (hereafter referred to as 'The Guide') specifies the guidance for assessing the acceptability of defects in welded structures based on failure assessment diagram (FAD) method. In this method, a design curve named as failure assessment curve is used in interpolating between the two failure criterions namely brittle fracture and plastic collapse (Figure 1). The safety of the assessed structure is determined by the relative position of the assessment point on the FAD. The relative position is derived from two separate set of calculations incorporating both brittle fracture and plastic collapse failure criterions. The final assessment procedure is then straightforward i.e. if the relative position of the point is inside the FAD curve, the structure is considered to be safe. 'The Guide' [1] specifies three levels of assessments using the FAD curves namely Option 1, Option 2 and Option 3 curves. The Option 1 curve of 'The Guide' [1] is given by 


$$
K_{\mathrm{r}}=\left(1-0.14 L_{\mathrm{r}}^{2}\right)\left[0.3+0.7 \exp \left(-0.65 L_{\mathrm{r}}^{6}\right)\right]
$$

where

$$
\begin{aligned}
& K_{\mathrm{r}}=\frac{\text { Stress intensity factor }}{\text { Fracture toughness }} \\
& L_{\mathrm{r}}=\frac{\text { Applied load }}{\text { Plastic collapse load }}
\end{aligned}
$$

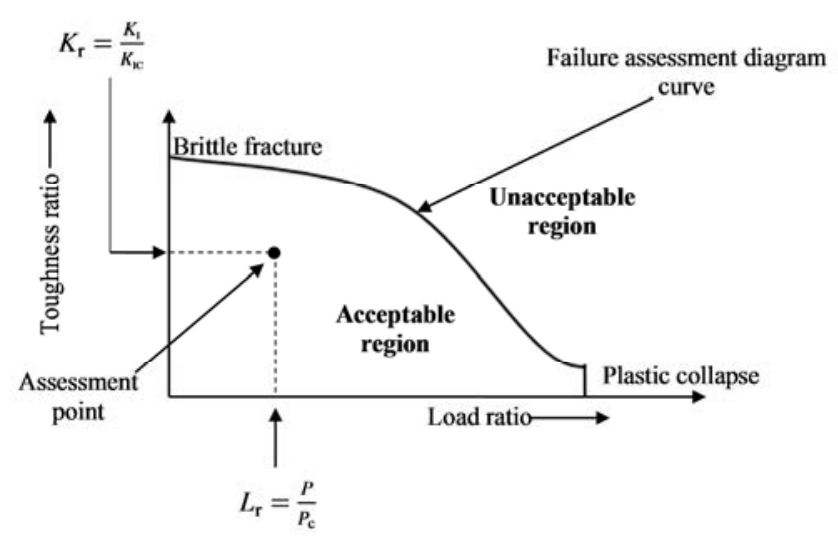

Figure 1. Safety assessment using FAD approach.

The $K_{\mathrm{r}}$ parameter of the FAD makes use of linear elastic stress intensity factor with no provision for the effect of plasticity on the crack driving force [2]. With the increasing value of $L_{\mathrm{r}}$, the effective crack tip driving force increases along with the plasticity effect. The fracture occurs when the elastic-plastic value of crack tip driving force reaches a critical value corresponding to the fracture toughness and is given by $\sqrt{E J_{\text {ep }}}=K_{\mathrm{IC}}$ [3]. Therefore, Eq. (2) can be modified as

$$
K_{\mathrm{r}}=\frac{K_{\mathrm{I}}}{K_{\mathrm{IC}}}=\sqrt{\frac{J_{\mathrm{e}}}{J_{\mathrm{ep}}}}
$$

With the increase in plasticity, the ratio of elastic $J$-integral to elastic-plastic $J$-integral decreases, whereby the FAD curves reduce in height and shift to the right-side along the abscissa.

The Option 1 curve in the 'The Guide' [1] is intended for general applications and is independent of the structural geometry and the material stress-strain curve of the specimen assessed. It was developed from extensive experimental databases of laboratory specimens [4]. Option 2 is more advanced than Option 1 by considering the flaws in stress gradients and the treatment of residual stresses. However, Option 2 is applicable for a limited ductile tearing. Option 3 is the most advanced of all the curves and it requires detailed data, computer analysis and significant technical knowledge and proficiency in assessment procedures. It is even suitable for materials with high strain-hardening capacity and for ductile materials that exhibit stable tearing. Therefore to obtain the most precise and optimal approach for any type of geometry, safety assessment using the Option 3 FAD curves is most recommended. In this study, Option 3 FAD curves are constructed for cracked multi-planar SHS TT-, YT- and KTjoints to validate the standard Option 1 curve of 'The Guide' [1] and to recommend optimal solutions that can safely be used to assess cracked multi-planar SHS TT-, YT- and KTjoints in practise.

\section{Numerical Modelling Using the New Finite Element (FE) Mesh Generator}

Complex three-dimensional geometry makes it challenging to create the Finite Element (FE) mesh model of cracked SHS welded joints by using commercial FE software's. Using a reliable automatic FE mesh generator that can model these complex cracked welded joints helps in saving considerable amount of time for the numerical analyses. In this study, an entirely new and robust FE mesh generator that can be used to model cracked multi-planar SHS TT-, YT- and KT-joints is developed. The meshing details, benefits of new automatic FE mesh generator and the validation of the results using the full-scale experimental test results are described in the following sub-sections.

\subsection{Meshing Details and the Benefits of Using the New FE Mesh Generator}

The nature of mesh geometry around the crack tip is the most pivotal feature in the numerical modelling of any flawed structure [5]. Collapse of elements around the crack tip especially for large scale deformation is a typical challenge observed in FE analysis. This will lead to nonconvergence of solutions resulting in inaccurate results. In elastic analyses, all nodes at the crack tip are normally tied and the mid-side node of the crack element is moved to the quarter $(1 / 4)$ point position to produce a $1 / r^{1 / 2}$ strain singularity. A typical construction of the crack tip elements used for elastic analyses is shown in Figure 2a. In the case of elastic-plastic analyses, a small plastic zone is formed at the crack tip region (Figure 2b). Therefore, the $1 / r^{1 / 2}$ strain singularity is no longer applicable at this region. In such cases, all elements surrounding the crack tip region produce a $1 / r$ strain singularity, which corresponds to the actual crack tip strain field for a fully plastic material [6].

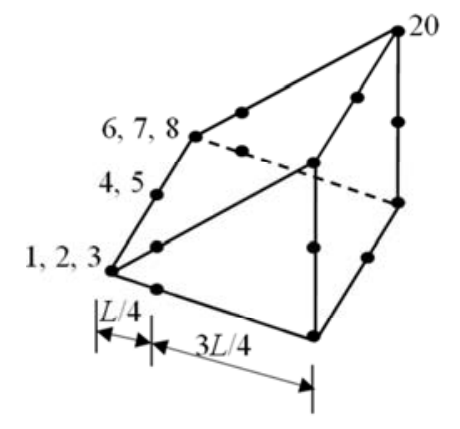

(a) For elastic analysis

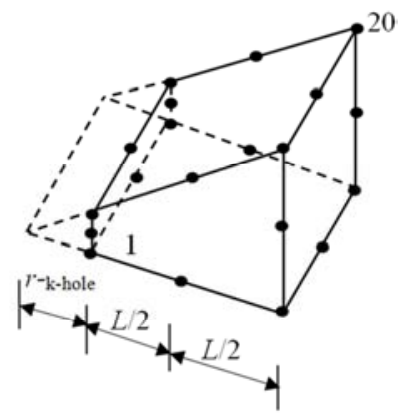

(b) For elastic-plastic analysis
Figure 2. Element types used at the crack tip. 
The new FE mesh generator addresses the issue of nonconvergence by using a key-hole for the modelling the crack tip in elastic-plastic analyses. It is recommended that the keyhole radius should be at least five times smaller than the tip radius in the deformed state [7]. For the new FE mesh generator, the key-hole radius is set as a variable so that an appropriate value can be chosen by the users. A value of $0.1 \mathrm{~mm}$ is observed to be sufficient to avoid the collapse of elements at the crack tip due to the large scale non-linear deformation. For the case of cracked multi-planar SHS TT-, YT- and KT-joints, the authors recommend a finite radius of key- hole from $0.05 \mathrm{~mm}$ to $0.15 \mathrm{~mm}$ with $0.1 \mathrm{~mm}$ as the most appropriate value for load values in the range of $1000 \mathrm{kN}$. The final generated crack tips for elastic and elastic-plastic analyses are shown in Figures 3 and 4, respectively.

Upon generation of crack tips, the next step is the creation of different mesh blocks which finally leads to generation of cracked multi-planar SHS TT-, YT- and KT-joints. The conventional dimensional notations used in the SHS joints are given in Figure 5 [8,9]. For the FE mesh generation of cracked multi-planar SHS TT-, YT- and KT-joints, zoning technique is used to generate the different mesh blocks. There are obvious advantages in using transition zones in any FE mesh generator. Firstly, it helps to reduce the number of elements in the FE mesh model. This will in turn reduce the analysis time of the FE mesh models. The pivotal regions such as crack front can be modelled with FE meshes of high mesh density and the regions that are further away from this region can be modelled with FE meshes of low mesh density. Secondly, it helps greatly in debugging the source code. Errors in models can be spotted and rectified locally due to the usage of different sub-zones. Furthermore, transition zones enable to connect parent crack block with adjacent mesh blocks easily.

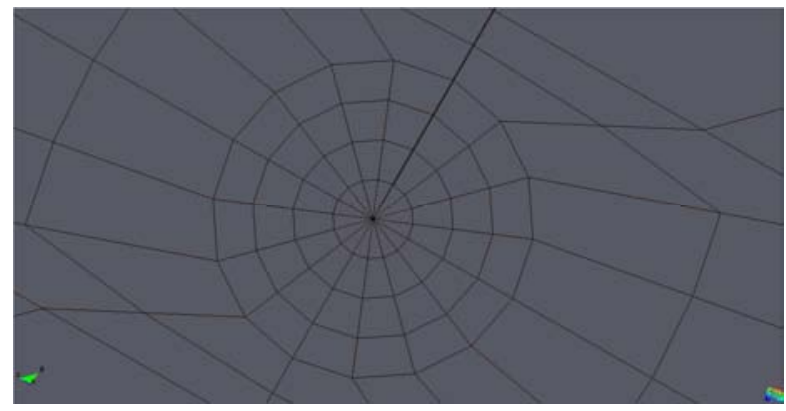

Figure 3. Elastic crack tip.

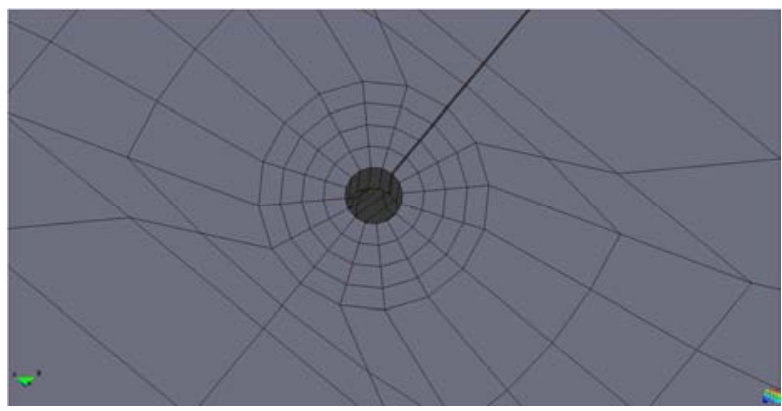

Figure 4. Elastic-plastic crack tip.
The parent brace part of cracked uni-planar SHS T-, Yand $\mathrm{K}$-joints is generated first. It is transformed into a complete cracked uni-planar SHS T-, Y- and K-joints by adding the chord parts on both sides. The number of divisions in both chord and brace parts is kept as a variable in the new FE mesh generator so that the user can conveniently decide the extent of mesh-refinement needed.

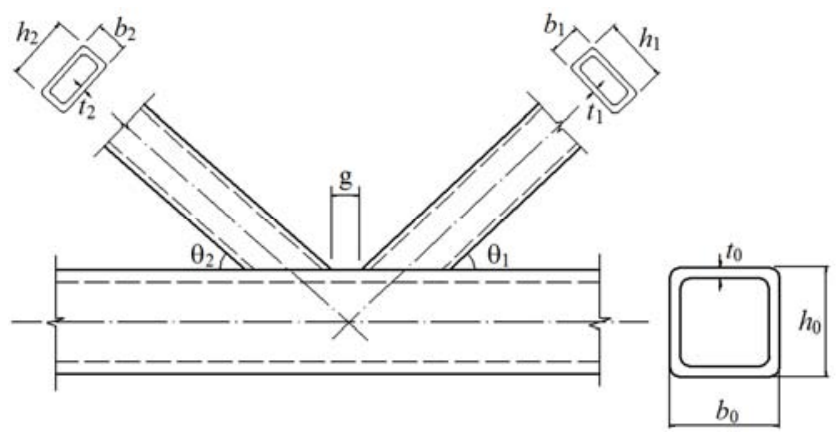

Figure 5. Dimensional notations used by CIDECT [8] and IIW [9].

The final step in numerical modelling using the new FE mesh generator is the creation of cracked multi-planar SHS TT-, YT- and KT-joints. This is achieved by adding the outof-plane multi-planar brace to the cracked uni-planar SHS T-, $\mathrm{Y}$ - and $\mathrm{K}$-joints. The out-of-plane brace is oriented in a direction perpendicular to the cracked uni-planar SHS T-, Yand $\mathrm{K}$-joint models. The geometrical dimensions of the outof-plane brace are kept identical to the parent brace part of uni-planar model for comparison purposes. The final completed FE mesh of typical cracked multi-planar SHS TT-, YT- and KT-joints are illustrated in Figures 6 to 8.

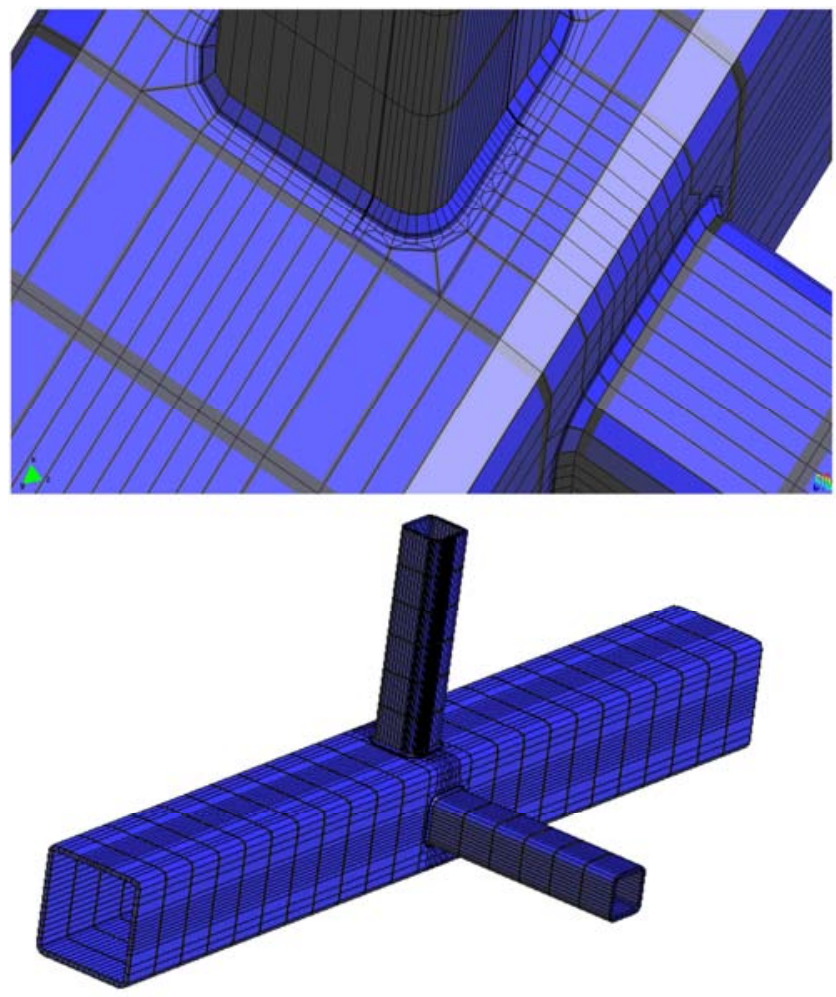

Figure 6. The completed FE mesh of a cracked multi-planar SHS TT-joint. 

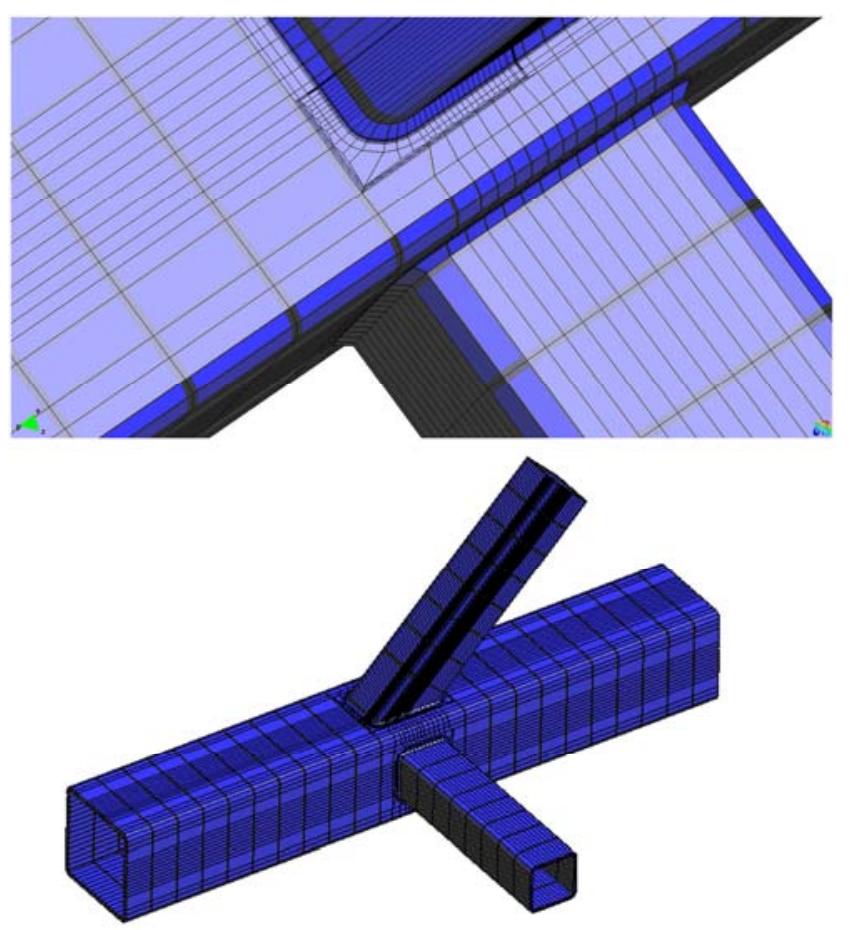

Figure 7. The completed FE mesh of a cracked multi-planar SHS YT-joint.
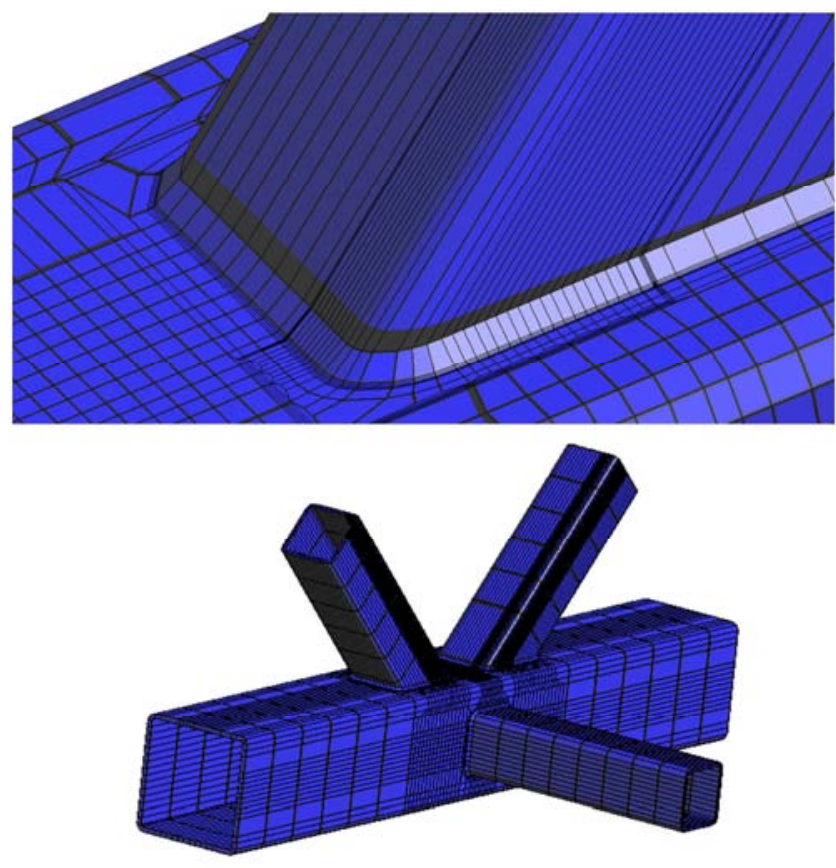

Figure 8. The completed mesh of a cracked multi-planar SHS KT-joint.

In addition to the experimental validation which is described in the next sub-section, features such as mesh convergence, mesh refinement and suitable aspect ratio are thoroughly checked to ensure the quality of the FE mesh. The new FE mesh generator is versatile to model cracks and geometries of random dimensions. The usage of only one type of element .i.e. 20 nodes hexahedral element eliminates the compatibility issues associated with mesh modelling. The new FE mesh generator is capable to address the limits of the previous mesh generating approaches by demonstrating the capability of achieving convergence of solutions even at a high plastic deformation. This capability is mainly attributed to features such as use of key-hole and single type of element. Another feature of the new FE mesh generator is the speedy generation of different types of cracked and uncracked models. For example, a typical cracked multiplanar SHS YT-joint with 20000 elements can be generated within 4 minutes. Further in-depth discussion about the validation and advantages of the new FE mesh generator is outside the main scope the current manuscript and it is available in other previously published works of the authors [10-14].

\subsection{Experimental Validation of the New FE Mesh Generator}

The new FE mesh generator is validated first against the experimental test results before it is used to carry out the parametric study of cracked SHS welded joints. A specifically designed test rig shown in Figure 9 is used to test the cracked SHS T-joints. The rig comprises of two servohydraulic actuators, which can produce $\pm 1000 \mathrm{kN}$ load and $\pm 125 \mathrm{~mm}$ displacement capacity respectively.

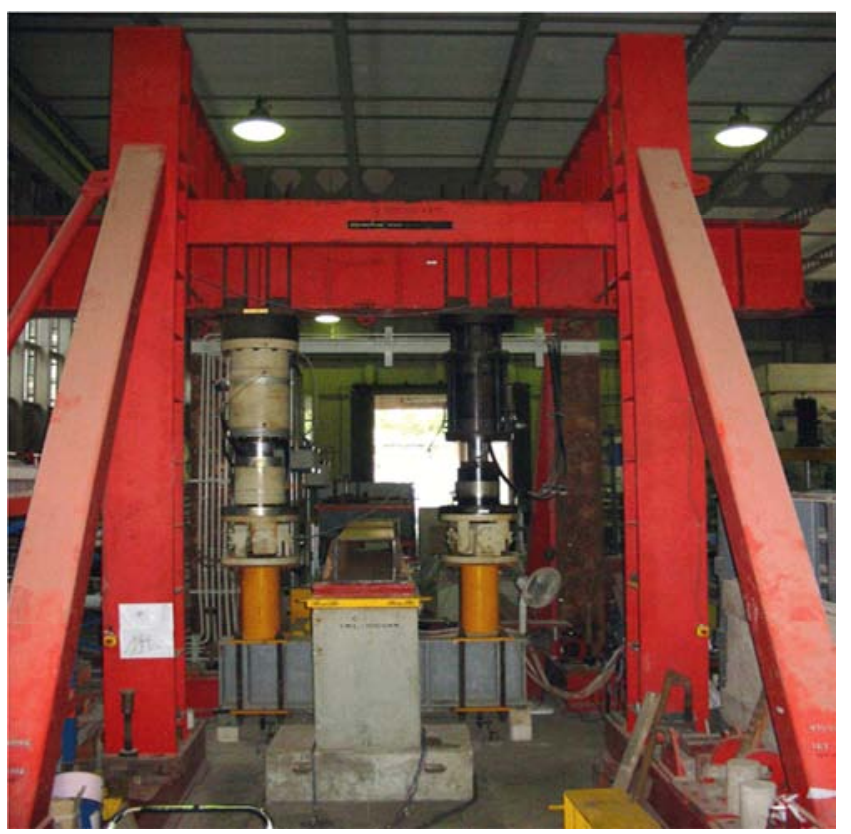

Figure 9. Test rig for SHS T-joint.

The loads are applied to the two ends of the spread beam by the actuators. Subsequently, the loads are transferred to the brace end via the 6 bolts stiffened to the spread beam as depicted in Figure 10. As a result, a total maximum axial load of $2000 \mathrm{kN}$ can be applied to the specimen. Instron 8500 controller is used to control the actuators. The controller can be set either in load control or in displacement control. Regarding the support condition at both chord ends, pinned end condition is created by using a pin and a roller placed on top of $600 \mathrm{~mm} \times 600 \mathrm{~mm}$ concrete supports as illustrated in Figure 10. For SHS Y- and K-joints, another test rig is used 
for the static tests as shown in Figure 11. The ends of the chord are fixed with the yellow rig as shown in Figure 12 for $\mathrm{Y}$ - and K-joints. Two hydraulic jackets are used to apply the loads on the end of the brace. Each hydraulic jacket can produce $1000 \mathrm{kN}$ load.

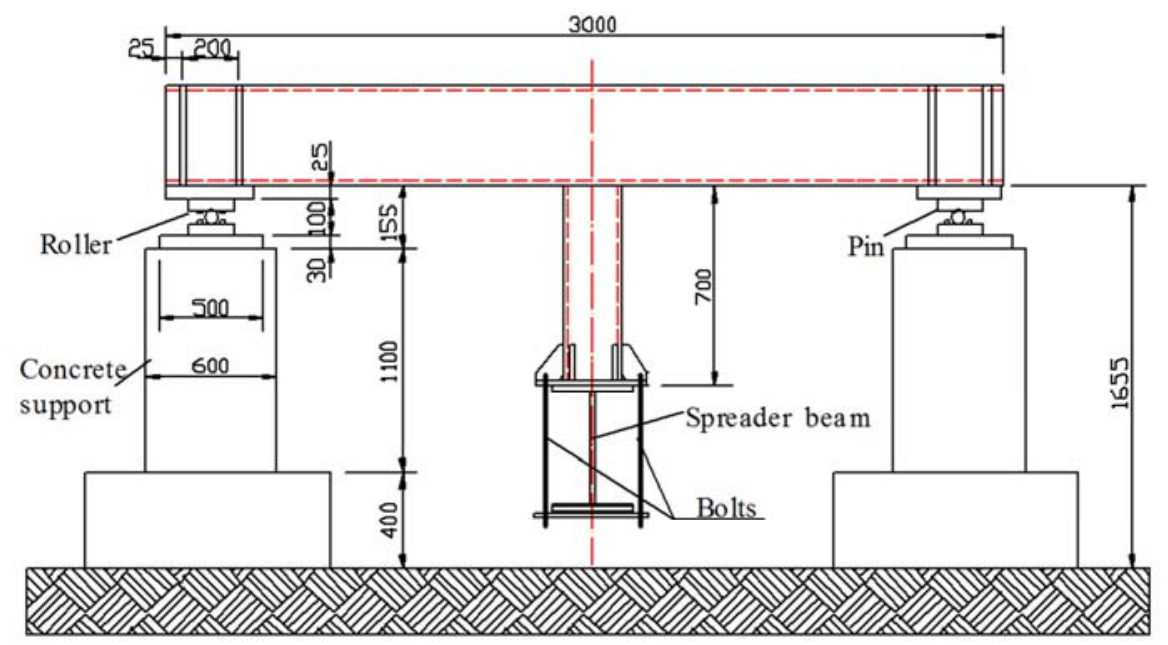

Figure 10. Setup of the experimental test.
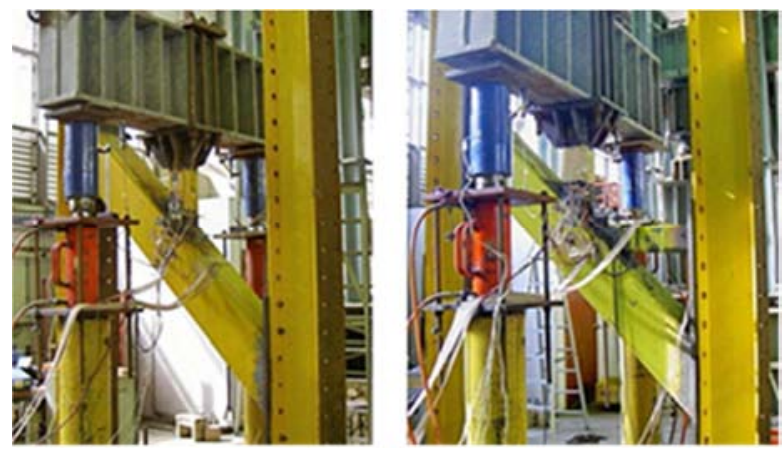

Figure 11. Test rig used to test the SHS Y- and K-joints.

The load-displacement curves clearly reveal the analogous trends between experimental and numerical models (Figures

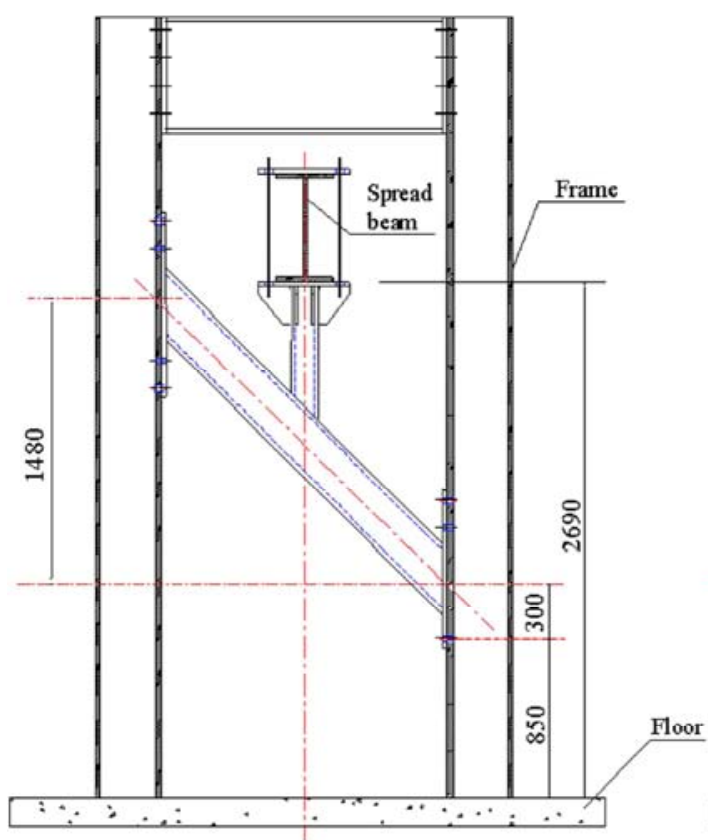

13 to 15). The tendency of the load-displacement curve obtained from numerical analyses being slightly above the experimental curve is most prominent in the case of SHS Kjoint. This is attributed to the fact that the numerical model is assumed to be perfect, and hence the stress-strain curve may not fully represent the actual condition in full-scale experimental tests. For instance, the stress-strain curve at the corner of the SHS joints is generally higher due to the strain hardening in the corner [15]. It is also observed that the postpeak unloading curves observed in the experimental results deviates from numerical curves. This deviation does not affect the accuracy of the results produced using the new FE mesh generator as there is good agreement with the experimental and numerical results for the load-displacement curves in the plastic-collapse region.

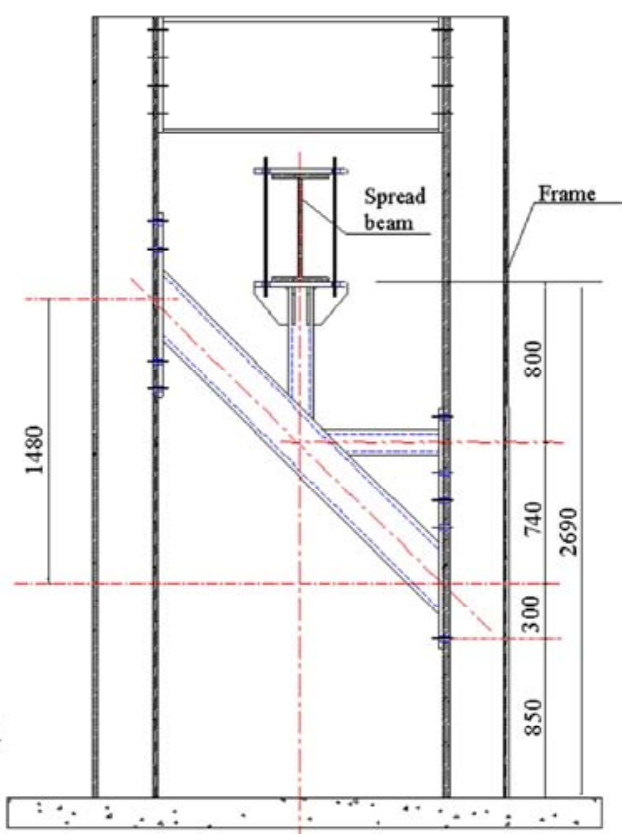

Figure 12. Schematic view of the test rig used to test the SHS Y-and K-joints. 


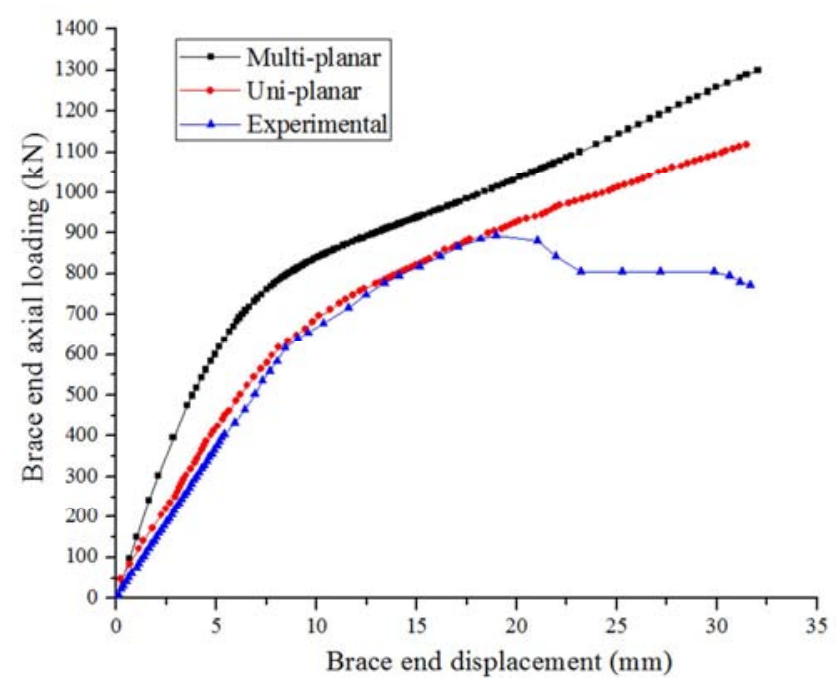

Figure 13. Comparison of load-displacement curves of uni-planar and multi-planar SHS T-joints.

Figure 13 shows the comparison of load-displacement curves for the uni-planar and multi-planar SHS T-joints. The plastic collapse $\left(P_{\mathrm{c}}\right)$ load of $934.39 \mathrm{kN}$ for the cracked multiplanar SHS TT-joint reveals a $15.87 \%$ increase of load when compared to the same cracked uni-planar SHS T-joint where the $P_{\mathrm{c}}$ load is $786.09 \mathrm{kN}$. This phenomenon is mainly attributed to the increase of stiffening effect caused by the additional multi-planar brace. Similarly, in the case of loaddisplacement curves for the cracked uni-planar and multiplanar SHS Y-joints, the $P_{\mathrm{c}}$ load is found to increase by $26.55 \%$ for cracked multi-planar SHS YT-joint (Figure 14). The $P_{\mathrm{c}}$ load values for cracked uni-planar and multi-planar SHS Y-joints are $853.65 \mathrm{kN}$ and $1161.33 \mathrm{kN}$, respectively.

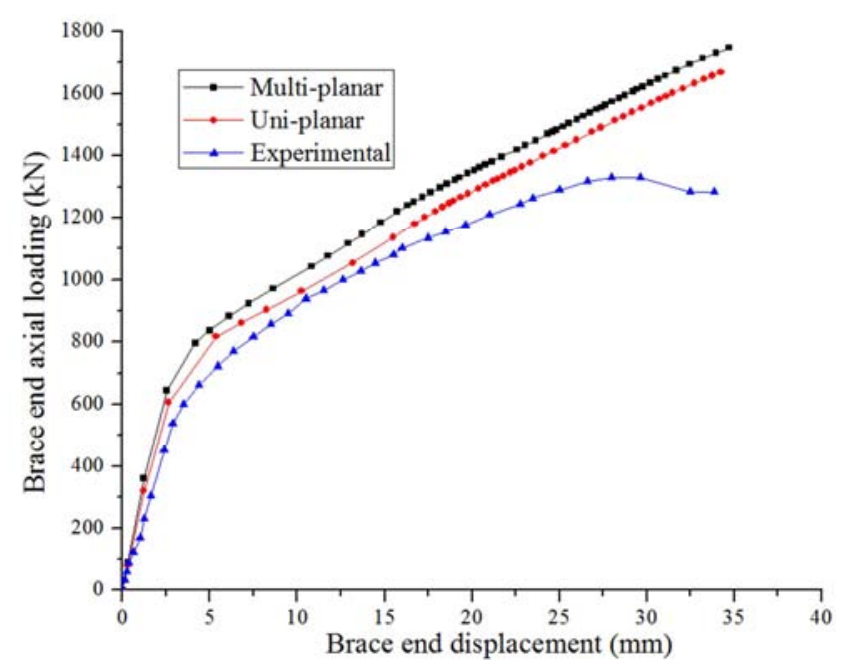

Figure 14. Comparison of load-displacement curves of uni-planar and multi-planar SHS Y-joints.

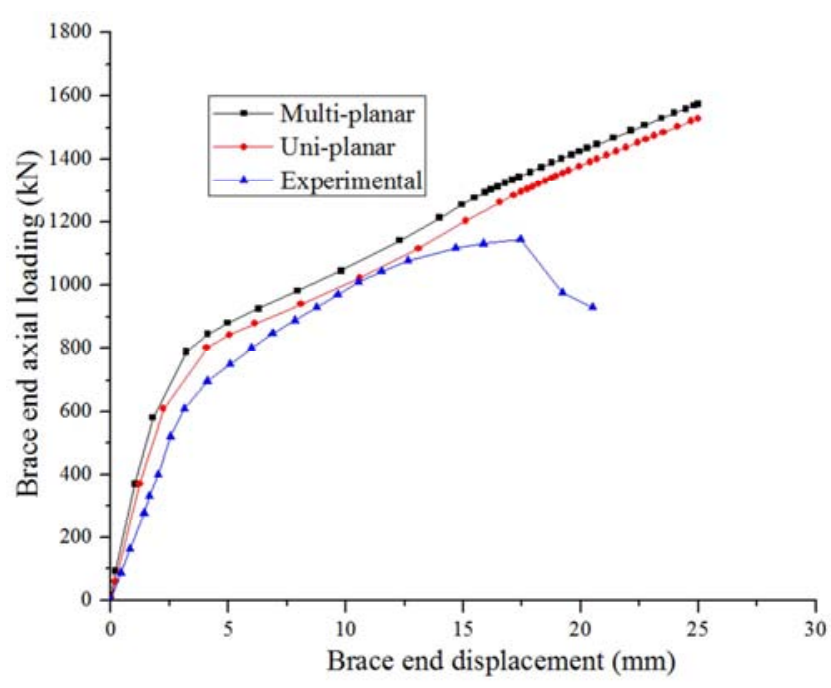

Figure 15. Comparison of load-displacement curves of uni-planar and multi-planar SHS K-joints.

In the case of load-displacement curves for the cracked uni-planar and multi-planar SHS K-joints, the $P_{\mathrm{c}}$ load is found to increase by $9.53 \%$ for cracked multi-planar SHS KT-joint (Figure 15). The $P_{\mathrm{c}}$ load values for cracked uniplanar and multi-planar SHS K-joints are $971.80 \mathrm{kN}$ and $1074.25 \mathrm{kN}$, respectively. It can be concluded from the comparison of all the three types of joints that the additional out-of-plane brace increases the $P_{\mathrm{c}}$ load of the cracked uniplanar SHS T-, Y- and K-joints. Validation of new FE mesh generator using both experimental and numerical results enables in carrying out the parametric study of cracked multiplanar SHS TT-, YT- and KT-joints.

\section{Parametric Study}

The material used in the present study is BS4360 structural steel of Grade 50D, and the stress-strain curve of the material is shown in Figure 16.

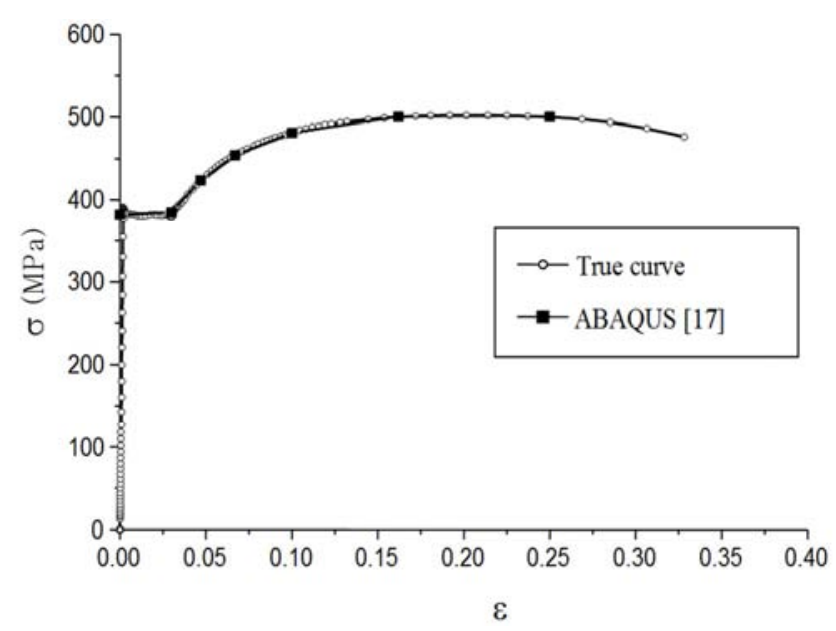

Figure 16. Stress-strain curve of the BS4360-50D structural steel.

The loads are applied using displacement control for the 
parametric study. The Young's modulus and Poisson's ratio of the material used are $210 \mathrm{kN} / \mathrm{mm}^{2}$ and 0.3 respectively. The cracked multi-planar SHS TT-, YT- and KT-joints are subjected to axial loading at the brace end. Regarding the boundary condition, the nodes at the brace and the chord ends are free and pinned, respectively. Throughout the present study, the chord length is kept constant at a value of $3000 \mathrm{~mm}$. The longer value of chord length guarantees that the effect of chord end boundary conditions on the failure of damaged joints is insignificant [10]. The details of various geometries used in the parametric study are given in Table 1.
Different values of $\beta$ are analyzed for percentage crack area values of $5.8 \%, 10 \%$ and $20 \%$. The values of $\beta$ vary from a lower limit of 0.25 to a higher limit of 0.75 . Stacey et al. [16] suggested that for eliminating the chord length to half chord width ratio $(\alpha)$ effect, a minimum $\alpha$ value of 8 is needed. In addition, the chord length should be at least four times the chord diameter [16]. The current research satisfies both the above recommendations, and therefore, the effect of $\alpha$ can be ignored. It was further recommended that chord half width to thickness ratio $(\gamma)$ has a minimal effect on the $P_{\mathrm{c}}$ load for $\beta$ up to 0.8 .

Table 1. Dimensions of specimens for crack area of $5.8 \%, 10 \%$ and $20 \%$.

\begin{tabular}{|c|c|c|c|c|c|c|c|c|c|}
\hline$b_{1}$ & $b_{2}$ & $t_{0}$ & $t_{1}$ & $l_{\mathrm{c}}$ & $\beta$ & $b_{0}$ & $\gamma$ & $\alpha$ & $\tau$ \\
\hline 150.0 & 150.0 & 16 & 16 & 3000 & 0.25 & 600.0 & 18.8 & 10.0 & 1 \\
\hline 150.0 & 150.0 & 16 & 16 & 3000 & 0.30 & 500.0 & 15.6 & 12.0 & 1 \\
\hline 150.0 & 150.0 & 16 & 16 & 3000 & 0.35 & 428.6 & 13.4 & 14.0 & 1 \\
\hline 150.0 & 150.0 & 16 & 16 & 3000 & 0.40 & 375.0 & 11.7 & 16.0 & 1 \\
\hline 150.0 & 150.0 & 16 & 16 & 3000 & 0.45 & 333.3 & 10.4 & 18.0 & 1 \\
\hline 150.0 & 150.0 & 16 & 16 & 3000 & 0.50 & 300.0 & 9.4 & 20.0 & 1 \\
\hline 150.0 & 150.0 & 16 & 16 & 3000 & 0.55 & 272.7 & 8.5 & 22.0 & 1 \\
\hline 150.0 & 150.0 & 16 & 16 & 3000 & 0.65 & 230.8 & 7.2 & 26.0 & 1 \\
\hline 150.0 & 150.0 & 16 & 16 & 3000 & 0.70 & 214.3 & 6.7 & 28.0 & 1 \\
\hline 150.0 & 150.0 & 16 & 16 & 3000 & 0.75 & 200.0 & 6.3 & 30.0 & 1 \\
\hline
\end{tabular}

\subsection{Calculation and Validation of J-integral}

For ductile materials, the elastic theory may not be sufficient to adequately study the crack initiation/propagation behaviour. It is attributed to the fact that the ductile materials absorb more energy prior to crack initiation and its subsequent growth. Therefore, it becomes necessary to employ other approaches such as the use of plasticity theory to measure the energy required for crack initiation and propagation. $J$-integral is a volume integral formulation which is frequently employed for the elastic-plastic analyses of ductile materials. For the current study, the $J$-integral is calculated using the virtual crack extension (VCE) technique which is built in ABAQUS software [17]. It interprets the $J$ integral as a function of location along the crack front which provides the decrease in total potential energy of the loaded structure caused by an increase in the crack opening area at that same position on the crack front.

ABAQUS software [17] formulates this as follows:

$$
-\delta P=\int_{s} J(s) \cdot \delta l(s) \mathrm{d} s
$$

where $\delta P$ is the change in the structure's total potential energy, $s$ is the coordinate which identifies position along the crack front, $J(s)$ is the $J$-integral value and $\delta l(s)$ is the advance of the crack front normal to itself and in the local plane of the crack at this point.

The value of $J(s)$ and the VCE are then interpolated from the value at crack front nodal position using the same order of interpolation as used in the elements adjoining the crack front. Thus, Eq. (5) becomes, in the FE model, a set of equations which relate the set of total potential energy changes produced by crack advances at each crack front nodal position to the $J$-integral values of the same crack front nodal positions. Once these values are determined, the equations can be solved for these nodal positions values of $J$ integral. The method is specifically suitable because it is simple to use, time saving and provides good accuracy [18].

The $J$-integral results obtained from the new FE mesh generator is further validated with those obtained from the FEACrack $^{\mathrm{TM}}$ software [19] as well as with the previously published results [15]. The comparison with FEACrack ${ }^{\mathrm{TM}}$ software [19] reveals maximum percentage differences of $0.09 \%$ and $7.89 \%$ at the deepest point and at the ends of crack, respectively (Figure 17).

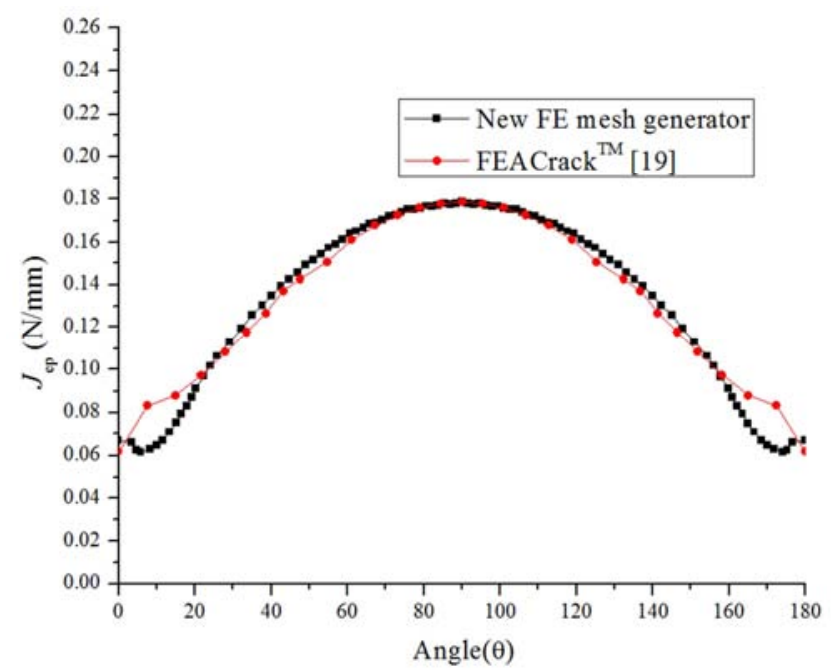

Figure 17. Comparison of J-integral values obtained using new FE mesh generator and FEACrack ${ }^{T M}$ [18].

The pattern of variation and the convergence of solutions 
for compared results reaffirms the suitability of using the new FE mesh generator. For cracked uni-planar SHS T-, Yand $\mathrm{K}$-joints, FAD curves are constructed using the new FE mesh generator and are further compared with the previously published FAD curves [15]. Figures 18 to 20 represent the constructed FAD curves for SHS T-, Y- and K-joints, respectively. The comparison with the previously published FAD curves [15] reveals close similarity and it further verifies the suitability of using the new FE mesh generator for constructing the FAD curves for cracked multi-planar SHS TT-, YT- and KT-joints.

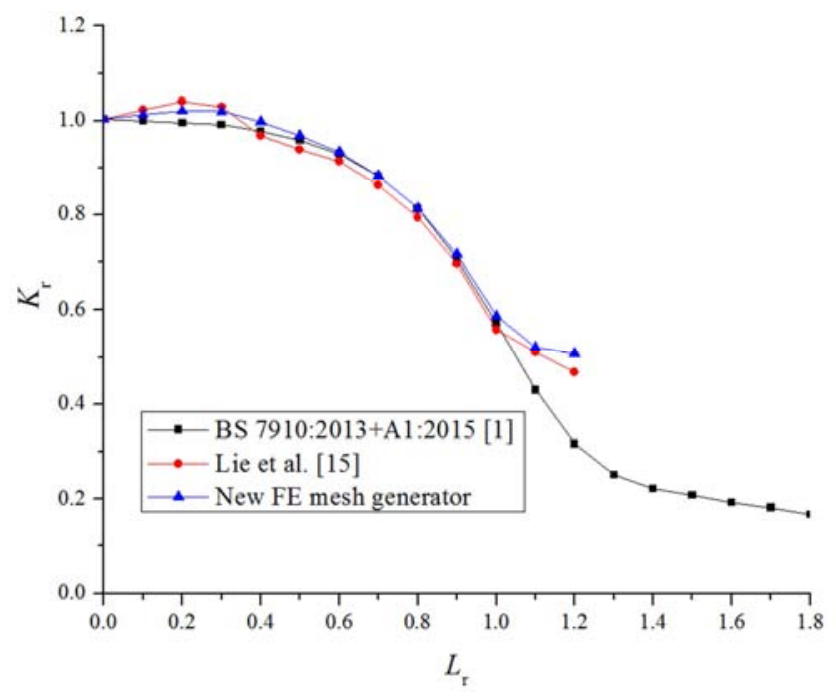

Figure 18. Comparison of FAD curves of cracked uni-planar SHS T-joints.

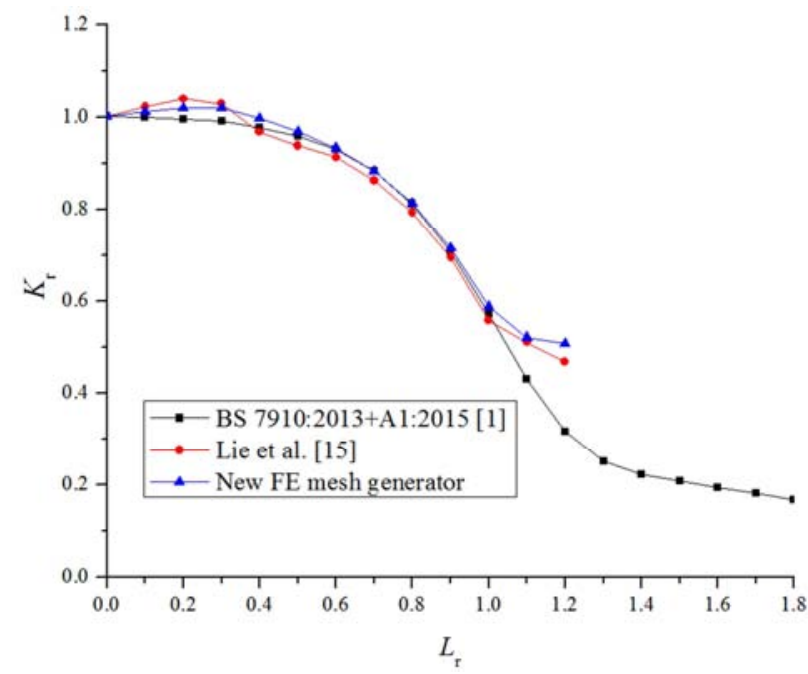

Figure 19. Comparison of FAD curves of cracked uni-planar SHS Y-joints.

\subsection{Plastic Collapse Load}

In practise, the joint assessments are performed so as to prevent likely failure mechanisms such as the gross plastic deformation [10]. It is carried out to guarantee that the design of service loads, stresses, and strains confine to the stated limits defined in the codes of practise such as 'The Guide' [1]. The elastic behaviour of steel can be classified as linear till yield and non-linear after yield. The capability of steel to support higher stress after yielding is attributed to the above mentioned non-linear behaviour (strain hardening) [10].

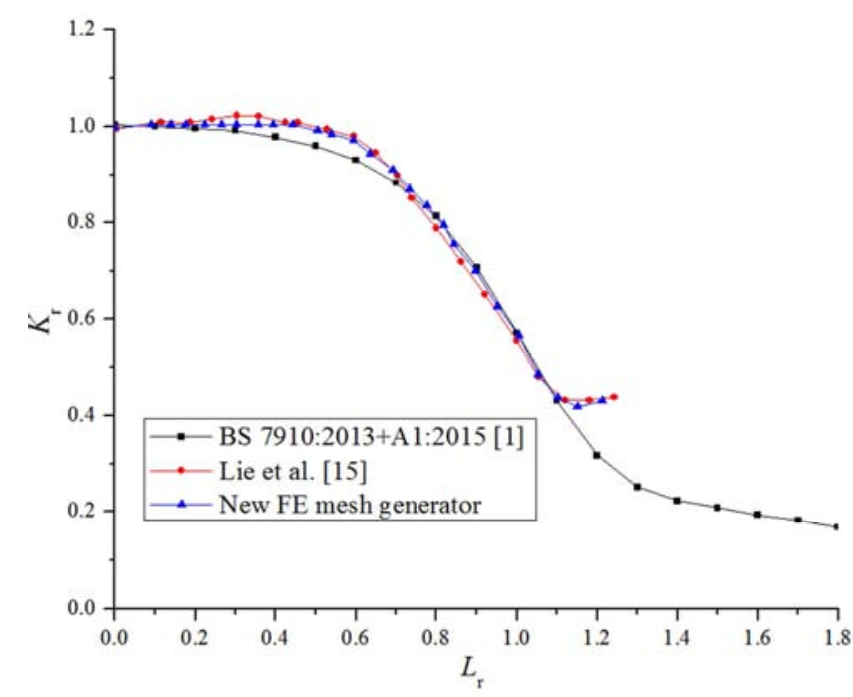

Figure 20. Comparison of FAD curves of cracked uni-planar SHS K-joints.

Typical load-displacement curves from the present study for both cracked and uncracked multi-planar SHS TT-joints are depicted in Figure 21.

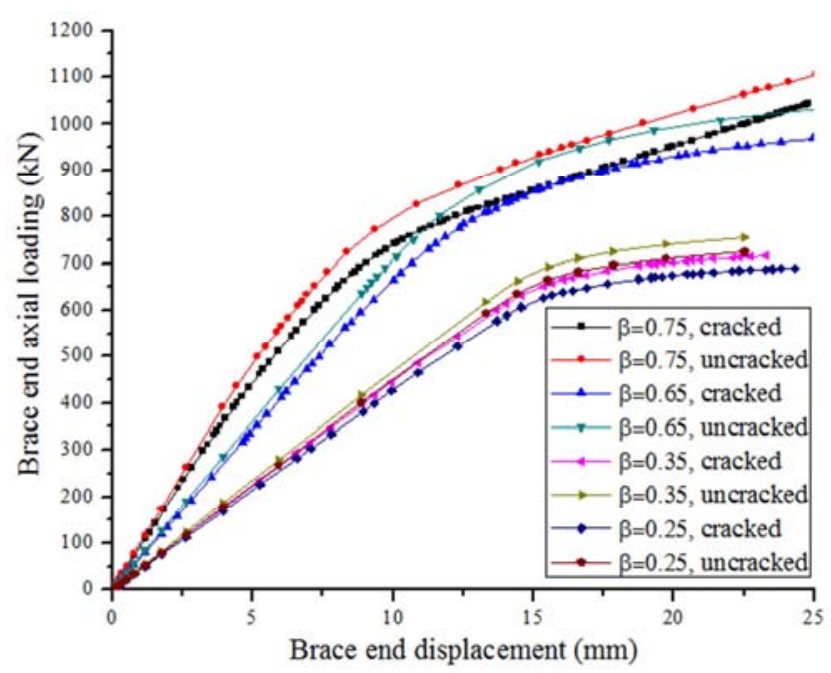

Figure 21. Typical load vs displacement curve for crack area $20 \%$ for multiplanar TT-joints.

It is revealed that the the load-carrying capacity of the SHS TT-joint is reduced by the presence of surface cracks. In the present study, the allowable static load of the multi-planar SHS welded joints is calculated by defining a plastic collapse load. The criterion used to define plastic collapse load is the twice-elastic compliance (TEC) criterion. This criterion describes a load limit at which plastic deformation becomes excessive preceding the physical collapse. Various previous studies have used the TEC criterion to determine the $P_{\mathrm{c}}$ load of cracked tubular joints $[15,20,21]$. This plastic criterion is described in ASME VIII Division 2 [22] as the twice-elastic slope (TES) criterion.

The TEC criterion is established on the load-deformation 
response of a structure in the plastic analysis as shown in Figure 22. The $P_{\mathrm{c}}$ load is the load corresponding to the intersection of the load-deformation curve and the twice elastic compliance line [10]. The twice elastic compliance line start from the origin of the load-deformation curve and has twice the slope of the initial elastic response, which is obtained using the equation

$$
\tan \phi=2 \tan \theta
$$

where $\varphi$ and $\theta$ are the angles measured from the load axis as shown in Figure 22.

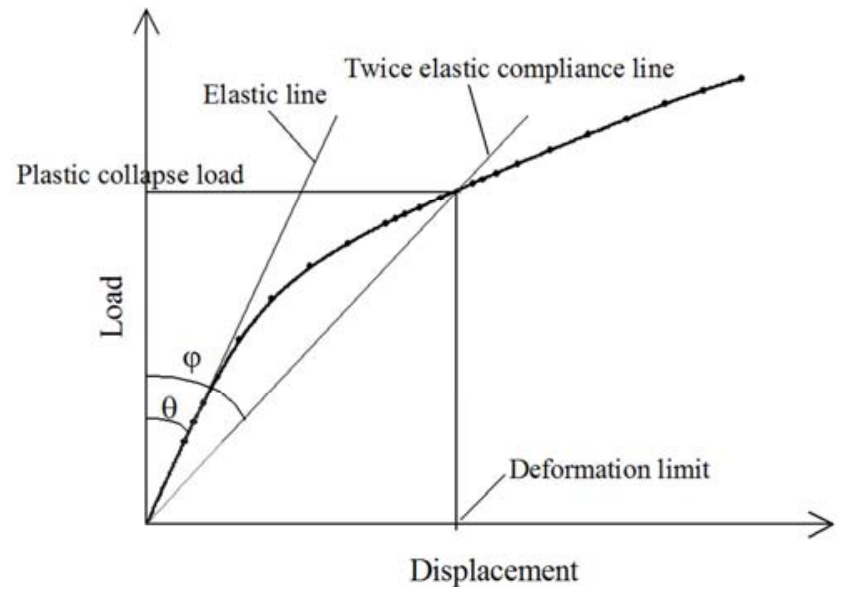

Figure 22. Twice elastic compliance criterion.

\section{Failure Assessment Diagrams (FADs) of Cracked Multi-planar SHS Welded Joints}

After validation of $J$-integral values produced from the new FE mesh generator, it can then be used for fracture analysis of cracked multi-planar SHS TT-, YT- and KTjoints. Figure 23 illustrates both the numerical model and the real fractured sample from experimental tests. Punching shear failure mode is observed for both numerical and experimental cracked joints.

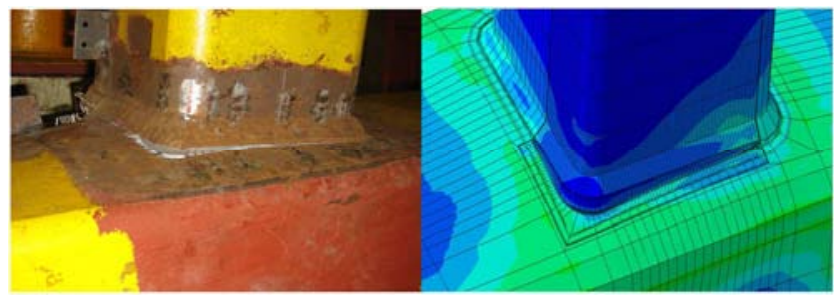

Figure 23. Comparison with real fractured sample.

On completion of both elastic and elastic-plastic analyses using the ABAQUS software [17], elastic $\left(J_{\mathrm{e}}\right)$ and elasticplastic $J$-integral $\left(J_{\text {ep }}\right)$ values are obtained, respectively.
Option 3 FAD curves are constructed for cracked multiplanar SHS TT-, YT- and KT-joints using the elastic $\left(J_{\mathrm{e}}\right)$ and elastic-plastic $J$-integral $\left(J_{\text {ep }}\right)$ values and the plastic collapse load $\left(P_{\mathrm{c}}\right)$. Figures 24 to 26 represent the constructed FAD curves for cracked multi-planar SHS TT-, YT- and KT-joints, respectively.

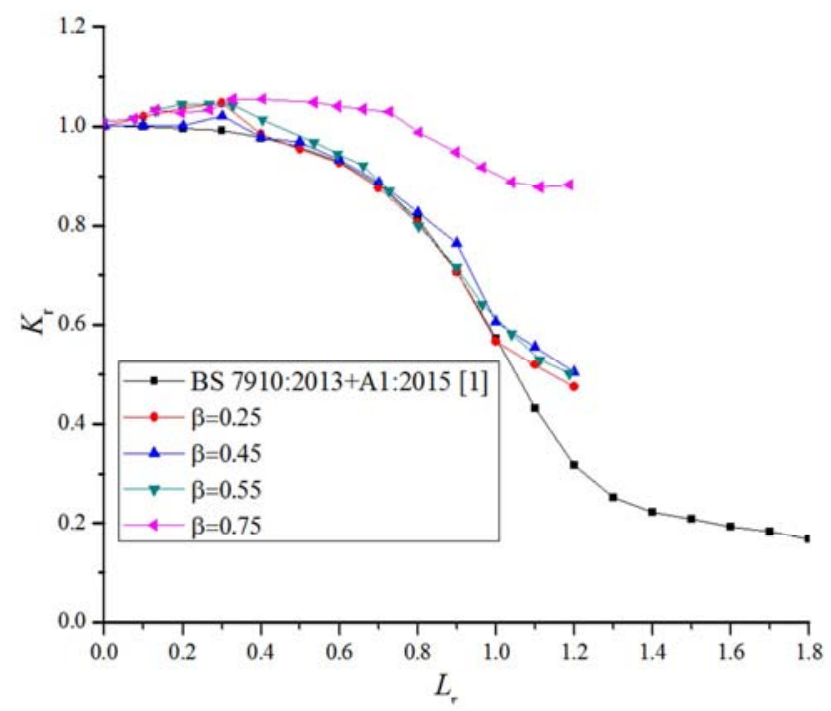

Figure 24. FAD curves of cracked multi-planar SHS TT-joints.

The significant observation from the constructed FAD curves is that some of the curves are located below the standard Option 1 curve of 'The Guide' [1] (Figures 24 to 26). The above observation is evident towards the right side of the FAD curves which is near to the plastic-collapse region in the Option 1 curve. The tendency of constructed FAD curves falling below the standard Option 1 curve is not desirable. As mentioned previously, the integrity of the structure is assessed by the relative position of the assessment point on the standard FAD curve (Figure 1).

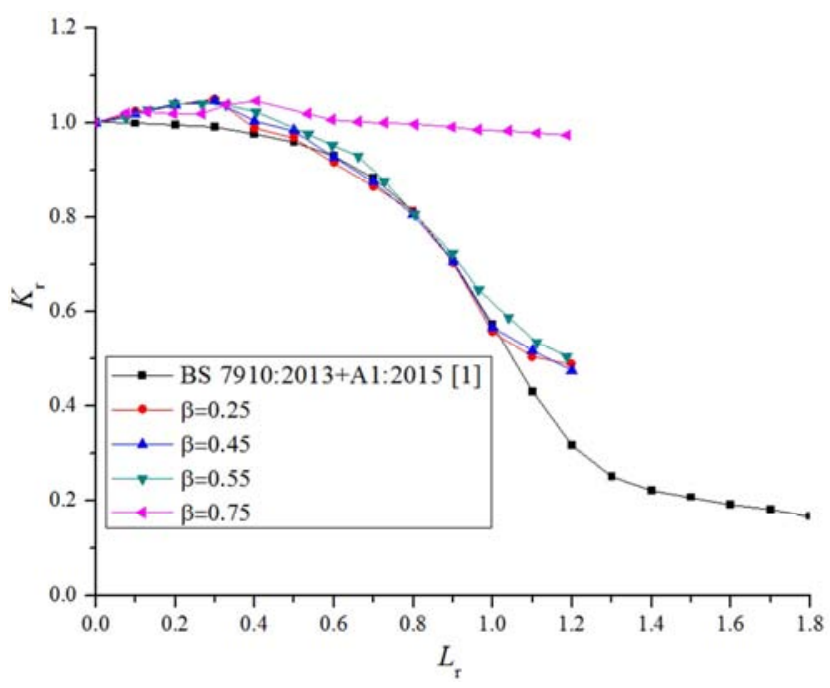

Figure 25. FAD curves of cracked multi-planar SHS YT-joints. 


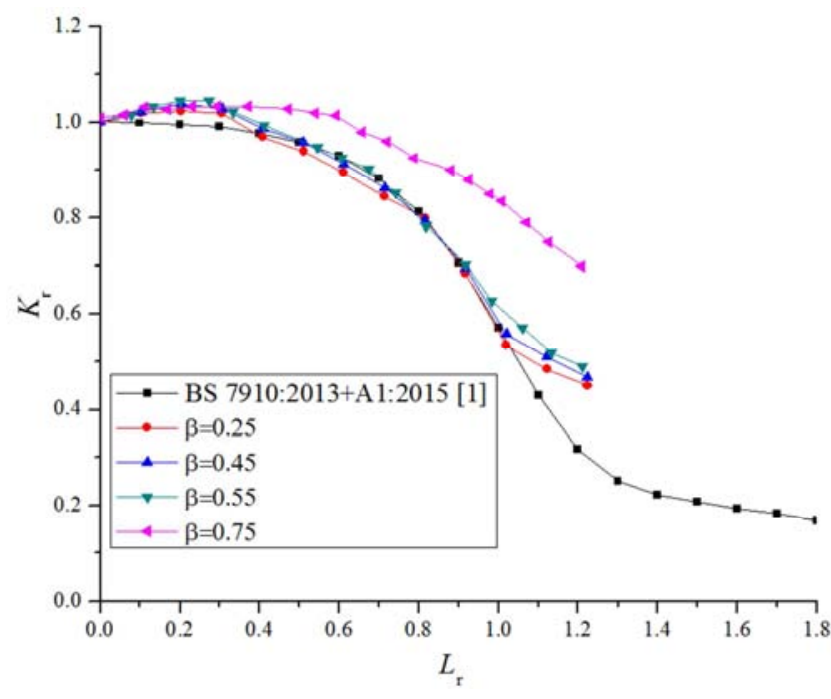

Figure 26. FAD curves of cracked multi-planar SHS KT-joints.

From the observation revealed in Figures 24 to 26, if an assessment point is located in the intermediate region (the region below the standard FAD curve and above the constructed FAD curves), it can falsely be assumed to be safe. The current research proposes a solution to this assessment issue for cracked multi-planar SHS TT-, YT- and KT-joints by recommending a penalty factor for plasticcollapse load which is explained in next paragraph. Furthermore, the results depicted that the constructed FAD curves for cracked multi-planar SHS TT-, YT- and KT-joints with low brace to chord width ratio $(\beta)$ are located below the Option 1 curve of 'The Guide' [1] when compared to the joints with higher $\beta$ ratio. This observation is due to the increase of plastic collapse load of cracked multi-planar SHS TT-, YT- and KT-joints with increasing value of $\beta$.

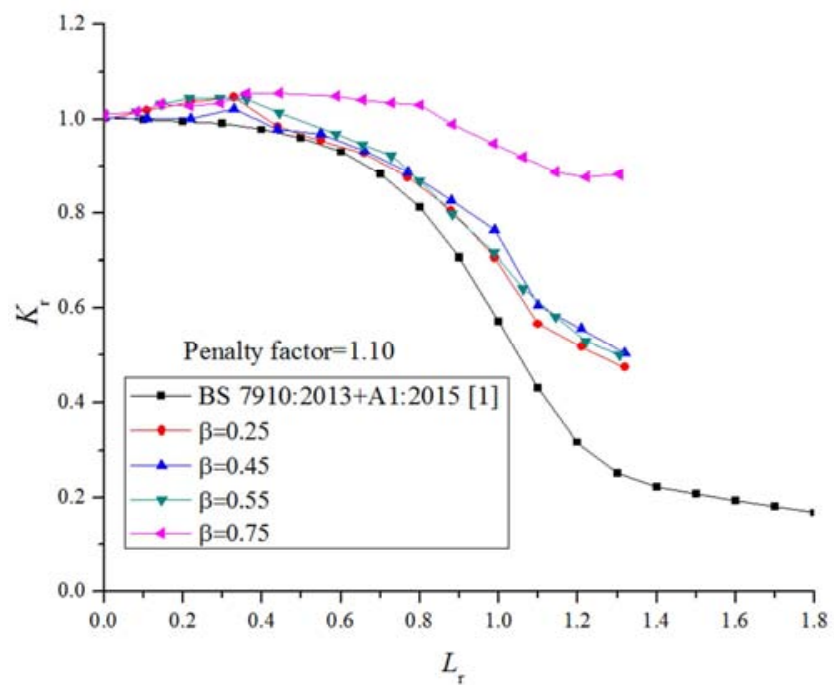

Figure 27. FAD curves of cracked multi-planar SHS TT-joints with a penalty factor of 1.10 .

The above results reveals a need to provide optimal solutions for safety and integrity assessment of cracked multi-planar SHS TT-, YT- and KT-joints. The present study proposes a straightforward approach to optimise the solution by proposing a penalty factor of 1.10 which is to be used while calculating the plastic collapse load cracked multiplanar SHS TT-, YT- and KT-joints. In other words, the recommended penalty factor of 1.10 is introduced to Eq. (3) whereby the plastic collapse load of the assessed structure is divided by a factor of 1.10 so that a conservative value of the plastic collapse load ratio is used to construct the FAD curves. Figures 27 to 29 shows the constructed FAD curves for cracked multi-planar SHS TT-, YT- and KT-joints with the newly introduced penalty factor of 1.10 .

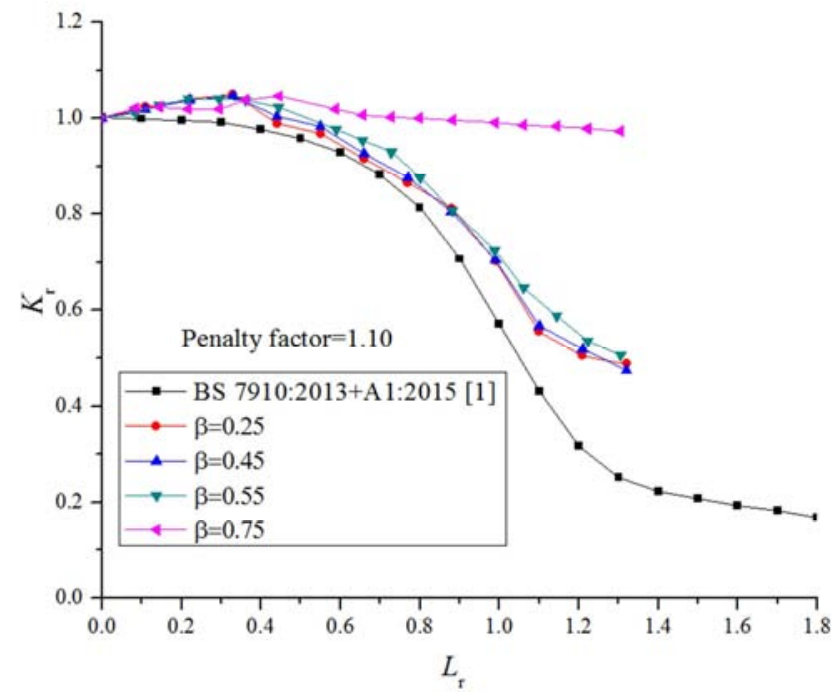

Figure 28. FAD curves of cracked multi-planar SHS YT-joints with a penalty factor of 1.10 .

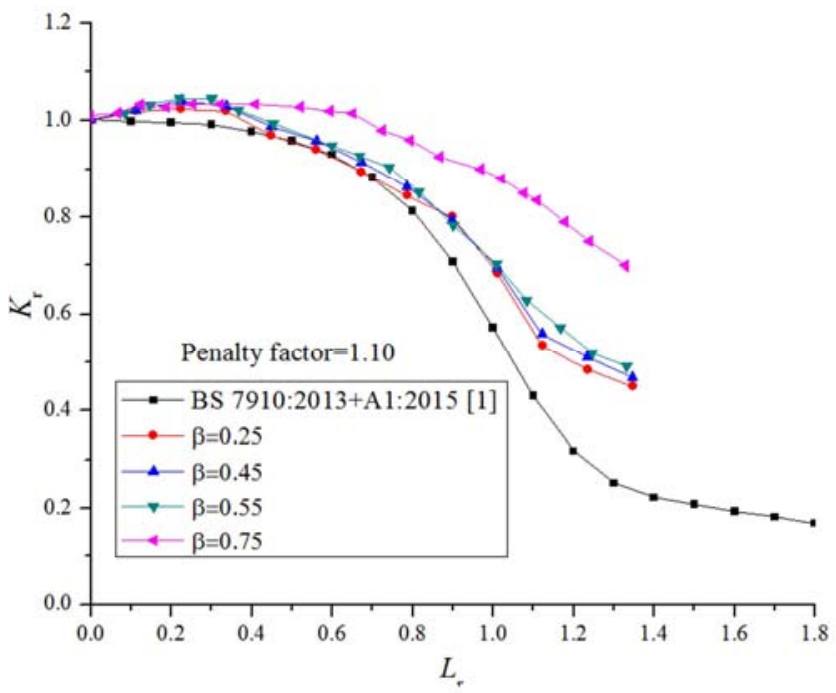

Figure 29. FAD curves of cracked multi-planar SHS KT-joints with a penalty factor of 1.10 .

It can be seen that all the newly constructed FAD curves lie just above the standard Option 1 curve of 'The Guide' [1]. Introduction of the penalty factor of 1.10 guarantees that there are no more assessment points, which are located at the intermediate region (the region below the standard FAD curve and above the constructed FAD curves in Figures 24 to 
26). Therefore, an optimised assessment approach for cracked multi-planar SHS TT-, YT- and KT-joints is achieved and this can be made use by researchers and practising engineers.

\section{Conclusion}

In order to assist in safety assessment of damaged multiplanar SHS welded joints, the present study develops a completely new and robust finite element (FE) mesh generator. The new FE mesh generator is capable to model cracks and geometries of arbitrary dimensions and is able to achieve convergence of solutions even at a high plastic deformation. It is shown to be aiding in speedy generation of cracked FE mesh models which is otherwise time consuming to generate using commercial software packages. The validation is done using the experimental test results as well as with the existing commercial software results. Subsequently, extensive parametric studies are carried out for cracked multi-planar SHS TT-, YT- and KT-joints. The highest level, Option 3 FAD curves of cracked SHS welded joints are constructed using the full numerical results of the elastic $J$-integral, elastic-plastic $J$ integral values and the plastic collapse load values. The constructed Option 3 FAD curves are further used to validate the standard Option 1 FAD curve of the 'The Guide'. It is found that standard Option 1 FAD curve of the 'The Guide' is not always safe in assessing the safety and integrity of cracked multi-planar SHS TT-, YT- and KT-joints.

For obtaining a safe and conservative safe prediction, a penalty factor of 1.10 is recommended for cracked multiplanar SHS TT-, YT- and KT-joints. The plastic collapse load of the assessed structure is divided by a factor of 1.10 so that a conservative value of the plastic collapse load ratio is used to construct the FAD curves. It is seen that all the newly constructed FAD curves using the penalty factor are located above the standard Option 1 FAD curve of the 'The Guide' thereby providing optimal solutions for cracked multi-planar SHS TT-, YT- and KT-joints.

\section{Acknowledgements}

The authors would like to thank the Maritime Port Authority of Singapore for funding this research project under the Grant No. MPA 23/04.15.03 - RDP 005/06/031.

\section{Nomenclature}

$\begin{array}{ll}b_{0} & \text { chord width } \\ b_{1}, b_{2} & \text { brace width } \\ g & \text { gap distance } \\ h_{0} & \text { chord height } \\ h_{1}, h_{2} & \text { brace height } \\ J & J \text {-integral } \\ J_{\text {e }} & \text { elastic } J \text {-integral } \\ J_{\text {ep }} & \text { elastic-plastic } J \text {-integral }\end{array}$

\begin{tabular}{|c|c|}
\hline$K_{\mathrm{I}}$ & stress intensity factor \\
\hline$K_{\text {IC }}$ & fracture toughness \\
\hline$K_{\mathrm{r}}$ & fracture ratio using stress intensity factor \\
\hline$l_{\mathrm{c}}$ & chord length \\
\hline$L_{\mathrm{r}}$ & $\begin{array}{l}\text { ratio of applied load to plastic collapse load } \\
\text { applied load }\end{array}$ \\
\hline$P_{\mathrm{c}}$ & plastic collapse load \\
\hline$t_{0}$ & chord thickness \\
\hline$t_{1}, t_{2}$ & brace thickness \\
\hline$\alpha$ & chord length to half chord width ratio \\
\hline$\gamma$ & chord half width to thickness ratio \\
\hline$\tau$ & brace thickness to chord thickness ratio \\
\hline$\theta_{1}, \theta_{2}$ & brace to chord angle \\
\hline$\sigma$ & applied stress \\
\hline & principle strain \\
\hline
\end{tabular}

\section{References}

[1] BS 7910:2013+A1:2015, "Guide to methods for assessing the acceptability of flaws in metallic structures", British Standards Institution, London, 2015.

[2] Burdekin, F. M. and Yang, G. J., "Failure assessment diagrams for mixed mode loading and cracked tubular joints", Proceedings of $9^{\text {th }}$ International Conference on Fracture, ICF9, Sydney, 1997, pp. 27-37.

[3] Zerbst, U., Ainsworth, R. A. and Schwalbe, K. H., "Basic principles of analytical flaw assessment methods", International Journal of Pressure Vessels and Piping, 2000, 77, pp. 855-867.

[4] Milne, I., Ainsworth, R. A., Dowling, A. R. and Stewart, A. T., "Assessment of the integrity of structures containing defects", International Journal of Pressure Vessels and Piping, 1988, 32, pp. 3-104.

[5] Lo, S. H. and Lee, C. K., "Solving crack problems by an adaptive refinement procedure", Engineering Fracture Mechanics, 1992, 43, pp. 147-163.

[6] Vipin, S. P., "Safety and risk assessment of damaged multiplanar square hollow section (SHS) TT-, YT- and KT-joints", Ph.D. thesis, Nanyang Technological University, Singapore, 2015.

[7] API RP579, "Fitness-for-service", American Petroleum Institute, Washington, 2007.

[8] Packer, J. A., Wardenier, J., Zhao, X. L., van der Vegte, G. J. and Kurobane, Y., "Design guide for rectangular hollow section (RHS) joints under predominantly static loading", $2^{\text {nd }}$ ed. CIDECT 3, Geneva, 2009.

[9] IIW, "Static design procedure for welded hollow section joints - recommendations", International Institute of Welding, IIW Doc. XV-1329-09, IIW Doc. XV-E-09-400, 2005.

[10] Lie, S. T., Vipin, S. P. and Li, T., "New reduction factor for cracked square hollow section T-joints under axial loading", Journal of Constructional Steel Research, 2015, 112, pp. 221227. 
[11] Lie, S. T., Vipin, S. P. and Li, T., "New weld toe magnification factors for semi-elliptical cracks in double-sided T-butt joints and cruciform X-joints", International Journal of Fatigue, 2015, 80, pp. 178-191.

[12] Lie, S. T., Li, T. and Shao, Y. B., "Stress intensity factors of tubular T/Y-joints subjected to three basic loading", Advanced Steel Construction, 2016, 12(2), pp. 109-133.

[13] Lie, S. T., Vipin, S. P. and Li, T., "New reduction factor for cracked square hollow section multi-planar TT-, YT- and KTjoints", Engineering Structures, 2017, 139, pp. 108-119.

[14] Vipin, S. P., Kolios, A., Lie, S. T. and Wang, L., "New reduction factor for cracked square hollow section K-joints", Journal of Constructional Steel Research, 2018, 144, pp. 166175 .

[15] Lie, S. T., Yang, Z. M. and Gho, W. M., "Validation of BS7910:2005 failure assessment diagram for cracked square hollow section T-, Y- and K-joints", International Journal of Pressure Vessels and Piping, 2009, 86, pp. 335-344.

[16] Stacey, A., Sharp, J. V. and Nichols, N. W., "The influence of cracks on the static strength of tubular joints", Proceedings of $15^{\text {th }}$ International Conference on Offshore Mechanics and Arctic Engineering, Florence, 1996, pp. 435-450.

[17] ABAQUS, "Standard user's manual", Version 6.11, Hibbett, Karlsson \& Sorensen, Inc., Rhode Island, 2011.

[18] Aliabadi, M. H. and Rooke, D. P., "Numerical fracture mechanics", Kluwer Academic Publishers, Dordrecht, 1991.

[19] FEACrack ${ }^{\mathrm{TM}}$, “User's manual”, Version 3.2, Quest Integrity Group LLC., Seattle, 2010.

[20] Stacey, A., Sharp, J. V. and Nichols, N. W., "Static strength assessment of cracked tubular joints", Proceedings of 15th International Conference on Offshore Mechanics and Arctic Engineering, Florence, 1996, pp. 211-224.

[21] Muscat, M., Mackenzie, D. and Hamilton, R., "A work criterion for plastic collapse", International Journal of Pressure Vessels and Piping, 2003, 80, pp. 49-58.

[22] ASME VIII Division 2, "Rules for construction of pressure vessels", American Society of Mechanical Engineers, New York, 1998. 